\title{
Implementation of the 2017 American College of Cardiology/American Heart Association Guidelines on Hypertension in Clinical Practice
}

\author{
Poonam Mahato, MD, ${ }^{1}$ Rajan Ganesh, MD, ${ }^{2 *}$ Balaram Krishna Hanumanthu, MD, ${ }^{1}$ Yesha Patel Rana, MD, ${ }^{2}$ \\ Jin Ei Chan, MD, ${ }^{1}$ Tahmina Alam, DO, ${ }^{2}$ Deepika Misra, MD ${ }^{1}$ \\ ${ }^{1}$ Department of Internal Medicine, Division of Cardiology, Mount Sinai Beth Israel/Icahn School of Medicine at Mount Sinai, New York, NY \\ ${ }^{2}$ Department of Internal Medicine, Mount Sinai Beth Israel/Icahn School of Medicine at Mount Sinai, New York, NY
}

\begin{abstract}
Background: The 2017 American College of Cardiology (ACC)/American Heart Association (AHA) guidelines on hypertension recommend a threshold blood pressure (BP) of $\geq 130 / 80 \mathrm{mmHg}$ for diagnosis of hypertension and treating hypertension to a goal $\mathrm{BP}$ of $<130 / 80 \mathrm{mmHg}$. For this study, we assessed the rate of compliance to the $2017 \mathrm{ACC} / \mathrm{AHA}$ hypertension guidelines by internal medicine residents and cardiology fellows in clinics affiliated with a teaching hospital in New York, New York.

Methods: We conducted a retrospective medical records review for patients who had a clinical encounter at the internal medicine resident and cardiology fellow clinics from January to February 2019. To distinguish from adherence with prior guidelines, patients with BP of 130-139/80-89 mmHg (unless age $\geq 60$ years and systolic blood pressure [SBP] 140-149 mmHg without chronic kidney disease or diabetes) were included. The primary outcome was accurate assessment of uncontrolled BP in accordance with the 2017 ACC/AHA guidelines.

Results: Included in the analysis were 435 patients from the internal medicine resident clinic and 127 patients from the cardiology fellow clinic. Accurate assessment of uncontrolled BP was higher in the cardiology fellow clinic compared to the internal medicine resident clinic ( $29.1 \%$ vs $10.3 \%, P<0.001)$, even after adjusting for baseline characteristics differences between the 2 clinics. Multivariate regression analysis revealed that the type of clinic (internal medicine, odds ratio [OR] $0.27,95 \% \mathrm{Cl} 0.16-$ $0.47 ; P<0.001)$, established diagnosis of hypertension (OR 2.06, 95\% Cl 1.06-3.99; $P<0.001)$, and SBP (OR $1.16 \mathrm{per} \mathrm{mmHg}, 95 \% \mathrm{Cl}$ $1.11-1.22 ; P=0.031$ ) were independently associated with the primary outcome.

Conclusion: Cardiology fellows were better at identifying hypertension diagnosis thresholds and BP treatment goals in accordance with 2017 ACC/AHA guidelines compared to internal medicine residents.
\end{abstract}

Keywords: Compliance, guideline adherence, health plan implementation, hypertension

Address correspondence to Deepika Misra, MD, Department of Internal Medicine, Division of Cardiology, Mount Sinai Beth Israel/Icahn School of Medicine at Mount Sinai, 10 Union Square E, Ste. 2B, New York, NY 10003. Tel: (212) 844-8455. Email: deepika.misra@mountsinai.org

\section{INTRODUCTION}

The Seventh Joint National Commission Report (JNC 7) published in 2003 defined hypertension as systolic blood pressure $(\mathrm{SBP}) \geq 140 \mathrm{mmHg}$ or diastolic blood pressure $(\mathrm{DBP}) \geq 90 \mathrm{mmHg}$ and recommended treating blood pressure (BP) to a goal BP of $<140 / 90 \mathrm{mmHg}$ in the general population and $<130 / 80 \mathrm{mmHg}$ in patients with diabetes or chronic kidney disease (CKD). ${ }^{1}$ The Eighth Joint National Commission Report (JNC 8) published in 2014 revised the BP treatment goals to $<140 / 90$

*Dr Ganesh is now affiliated with the Division of Cardiology, Dartmouth-Hitchcock Medical Center, Lebanon, $\mathrm{NH}$.
$\mathrm{mmHg}$ for adults $<60$ years of age, $<150 / 90 \mathrm{mmHg}$ for adults $\geq 60$ years of age, and $<140 / 90 \mathrm{mmHg}$ for adults with diabetes or CKD, regardless of age. ${ }^{2}$ The 2017 American College of Cardiology/American Heart Association $(\mathrm{ACC} / \mathrm{AHA})$ hypertension guidelines ${ }^{3}$ incorporated information from more recent studies, especially the SPRINT (Systolic Blood Pressure Intervention Trial) trial, ${ }^{4}$ to establish stricter cutoffs for the diagnosis of hypertension and the treatment goals compared to the JNC guidelines. In summary, the ACC/AHA defined hypertension as SBP $\geq 130 \mathrm{mmHg}$ or DBP $\geq 80 \mathrm{mmHg}$ based on $\geq 2$ readings obtained on $\geq 2$ occasions. BP goal was $<130 / 80 \mathrm{mmHg}$ for all adults. Pharmacologic therapy was recommended for anyone with $\mathrm{BP} \geq 140 / 90 \mathrm{mmHg}$ and for patients with BP 130-139/80-89 mm and established atherosclerotic 
cardiovascular disease (ASCVD) or an ASCVD 10-year risk of $\geq 10 \%$.

A review of the literature revealed a few small studies ${ }^{5}$ that have reported variable rates of physician adherence to the JNC 7 and JNC 8 guidelines on hypertension. ${ }^{1,2}$ Between May 2012 and April 2013, a cross-sectional descriptive survey investigated 59 primary care physicians working in 33 primary health centers in the Aljouf region of the Kingdom of Saudi Arabia and found that $80 \%$ adhered to the JNC 7 guidelines on hypertension. ${ }^{6}$ From February 2004 to October 2004, a retrospective medical records review of 345 patients evaluated physician adherence to the JNC 7 guidelines on hypertension using 22 criteria in 6 community-based clinics in lowa and concluded that general adherence was $53.5 \% .^{7}$ A 2007 retrospective review of 251 medical records at West Virginia University, Charleston, found an overall BP goal achievement of $45.6 \%$ by internal medicine residents. ${ }^{8}$

Studies focusing on the 2017 ACC/AHA hypertension guidelines have primarily evaluated the change in incidence and prevalence rates of newly diagnosed hypertension. ${ }^{9}$ Our review of the literature showed a lack of studies assessing the implementation of the new guidelines in clinical practice. Specifically, to the authors' knowledge, the implementation of the 2017 ACC/AHA hypertension guidelines based on the physicians' levels of training has not been explored.

For this study, we assessed the rate of implementation of the hypertension diagnosis thresholds and treatment goals defined by 2017 ACC/AHA hypertension guidelines at the internal medicine resident and cardiology fellow clinics affiliated with a teaching hospital in a major city. We also explored the hypertension management practices by internal medicine residents and cardiology fellows.

\section{METHODS}

We reviewed the medical records of patients who had a clinical encounter at the internal medicine resident clinic and cardiology fellow clinic associated with Mount Sinai Beth Israel, a teaching hospital in New York, New York. The study periods for the internal medicine resident and cardiology fellow clinics were January 1 to January 31, 2019, and January 1 to February 28, 2019, respectively. The additional month for the cardiology fellow clinic study period was included to help offset the greater volume of patients seen in the internal medicine resident clinic.

Patients with recorded SBP $\geq 130 \mathrm{mmHg}$ or DBP $\geq 80 \mathrm{mmHg}$ during the clinical encounter were included in the study regardless of established diagnosis of hypertension. To avoid conflict with adherence to prior guidelines, patients whose BP would be considered appropriate by JNC $8^{2}$ guidelines were excluded from the study. Hence, the study included (1) all patients with DBP $80-89 \mathrm{mmHg}$, (2) all patients with SBP $130-139 \mathrm{mmHg}$, and (3) patients with SBP $140-149 \mathrm{mmHg}$ if they were $\geq 60$ years of age without a history of CKD or diabetes. To reduce observer bias, the patients who were seen in the clinic by the investigators of this study were also excluded.

The clinical progress notes from the encounters were reviewed, and the patients' demographic information (age, sex, body mass index, tobacco abuse), BP, relevant medical history, medication list, and the parameters to calculate ASCVD 10-year risk ${ }^{10}$ were noted. SBP and DBP were assessed as normal, elevated in isolation, or elevated in combination. Definitions of isolated SBP elevation (SBP $\geq 130 \mathrm{mmHg}$ and DBP $<80 \mathrm{mmHg}$ ) and isolated DBP elevation (SBP $<130 \mathrm{mmHg}$ and DBP $\geq 80 \mathrm{mmHg}$ ) were used to identify and differentiate these phenotypes. Serum cholesterol levels were noted from laboratory results obtained within 6 months prior to the clinic encounter. ASCVD 10year risk percentage was estimated for patients aged 40 to 79 years with adequate data in accordance with the calculator from the ACC website. ${ }^{11}$ Patients with established ASCVD-defined as coronary artery disease, prior myocardial infarction, peripheral artery disease, or cerebrovascular disease-were excluded from ASCVD 10-year risk calculation in accordance with recommendations.

For the purposes of this study, patients with uncontrolled BP included patients with known hypertension and BP not at goal (ie, SBP $\geq 130 \mathrm{mmHg}$ or DBP $\geq 80 \mathrm{mmHg}$ ) and patients who presented for their initial encounter with BP that would be considered in the hypertensive range (ie, SBP $\geq 130 \mathrm{mmHg}$ or DBP $\geq 80 \mathrm{mmHg}$ ) and who needed reassessment at future visits to confirm hypertension.

The primary outcome of the study was defined as the correct assessment of uncontrolled BP by physicians in accordance with the 2017 ACC/AHA guidelines. Physicians were noted to have correctly assessed uncontrolled BP if they fulfilled the following criteria: (1) For patients with an established diagnosis of hypertension, they mentioned in their clinic note that SBP $\geq 130 \mathrm{mmHg}$ or DBP $\geq 80 \mathrm{mmHg}$ was above goal, regardless of the intervention done; and (2) for patients without an established diagnosis of hypertension, they mentioned in their clinic note that SBP $\geq 130 \mathrm{mmHg}$ or DBP $\geq 80 \mathrm{mmHg}$ was elevated and would need to be reassessed.

The secondary outcome was defined as the type of intervention done once uncontrolled $\mathrm{BP}$ was correctly assessed. Interventions included prescribing a home BP monitor; providing advice on lifestyle changes, including the Dietary Approaches to Stop Hypertension (DASH) diet ${ }^{12}$; prescribing new antihypertensives; increasing the dose of existing medication; reviewing and reconciling medications; placing a consult to a specialist/hypertension nurse; and reassessing BP during the next visit.

Baseline characteristics were analyzed and summarized using descriptive statistics: mean \pm SD for continuous parametric variables, median and interquartile range for nonparametric data, and frequency (percentage) for categorical or nominal variables. Baseline continuous variables were compared between the 2 groups using $t$ test or nonparametric equivalent, and chi-square test (Fisher exact test in the case of sparse data) was used to compare categorical and nominal variables. Outcomes were assessed with logistic regression adjusting for risk factors described later in the text. Statistical significance was defined as a $P$ value of $\leq 0.05$. Data were analyzed using Stata, release 13 (StataCorp).

Approval for the study was granted by the institutional review board of the Mount Sinai School of Medicine. The authorization for use and disclosure of personal health information was waived because of minimal harm.

\section{RESULTS}

We reviewed 1,175 and 405 charts from the internal medicine resident and cardiology fellow clinics, respectively. After application of inclusion and exclusion criteria, 435 
(37.0\%) patients from the internal medicine resident clinic and $127(31.4 \%)$ patients from the cardiology fellow clinic were included for analysis $(n=562)$.

The baseline characteristics of the patients seen in the 2 clinics are displayed in Table 1. The mean ages of the patients seen at the cardiology fellow clinic and the internal medicine resident clinic were similar ( 57 years vs 59 years, $P=0.19$ ). The proportion of female patients was higher in the internal medicine resident clinic compared to the cardiology fellow clinic $(69.4 \%$ vs $48.0 \%, P<0.001)$. History of hypertension $(73.2 \%$ vs $58.9 \%, P=0.003)$ and established ASCVD (29.1\% vs $14.7 \%, P<0.001)$ were higher among patients seen in the cardiology fellow clinic vs the internal medicine resident clinic. Congestive heart failure $(15.7 \%$ vs $3.7 \%, P<0.001)$ and atrial fibrillation $(10.2 \%$ vs $3.7 \%$, $P=0.003$ ) were also more prevalent among patients seen in the cardiology fellow clinic vs the internal medicine resident clinic. Average SBP was higher among patients from the cardiology fellow clinic vs the internal medicine resident clinic $(132.5 \pm 6.7 \mathrm{mmHg}$ vs $131.0 \pm 7.3 \mathrm{mmHg}, P=0.042)$, whereas average DBP was lower for patients from the cardiology fellow clinic vs the internal medicine resident clinic (78.9 $\pm 7.7 \mathrm{mmHg}$ vs $80.8 \pm 5.9 \mathrm{mmHg}, P=0.004)$. The cardiology fellow clinic had a higher percentage of patients with isolated SBP elevation than the internal medicine resident clinic $(37.0 \%$ vs $24.8 \%, P=0.007$ ) and a lower percentage of patients with isolated DBP elevation than the internal medicine resident clinic (25.2\% vs $36.1 \%, P=0.022)$. Use of any antihypertensives (68.5\% vs $56.8 \%, P=0.014)$, beta blockers (44.9\% vs $15.6 \%, P<0.001)$, angiotensin converting enzyme inhibitors (ACEi)/angiotensin receptor blockers (ARB)/angiotensin receptor neprilysin inhibitors (ARNi) (54.3\% vs $40.0 \%, P=0.004)$, aspirin $(42.5 \%$ vs $32.0 \%$, $P=0.027$ ), and statins (63.0\% vs $49.7 \%, P=0.008)$ was also higher among patients seen in the cardiology fellow clinic compared to patients seen in the internal medicine resident clinic. Notably, body mass index, active tobacco abuse, history of diabetes, CKD stage $\geq 3$, cholesterol levels, and 10-year ASCVD risk for patients without established ASCVD were not statistically different between the 2 patient groups.

Accurate assessment of uncontrolled $\mathrm{BP}$ in accordance with ACC/AHA 2017 guidelines - the primary outcome of the study-occurred more frequently in the cardiology fellow clinic than the internal medicine resident clinic $(29.1 \%$ vs $10.3 \%, P<0.001$ ) (Table 2 ). The occurrence rates for the assignment of individual interventions are also shown in Table 2. Counseling regarding lifestyle changes was less frequently performed in the cardiology fellow clinic than in the internal medicine resident clinic ( $0 \%$ vs $3.4 \%, P=0.034)$. Compared to patients from the internal medicine resident clinic, patients from the cardiology fellow clinic had higher rates of prescriptions for new antihypertensives (3.9\% vs $1.1 \%, P=0.037)$, uptitration of the dose of antihypertensives (7.9\% vs $0.7 \%, P<0.001)$, reconciliation of antihypertensives (3.9\% vs $0.5 \%, P=0.002$ ), and planned reassessment at the next visit $(10.2 \%$ vs $3.0 \%, P<0.001)$. Differences in rates of home BP monitor prescriptions (3.9\% vs $2.3 \%, P=0.31)$ and referral to a specialist ( $0 \%$ vs $0.7 \%, P=0.35$ ) between cardiology fellow clinic patients and internal medicine resident clinic patients did not reach statistical significance.

Logistic regression was performed to identify factors associated with the primary outcome (Table 3 ). Secondary outcomes were not adjusted for, given the low event rate. In univariate analysis, significant predictors associated with accurate assessment of uncontrolled BP included clinic type, age, established diagnosis of hypertension, SBP, isolated DBP elevation, any antihypertensive use, beta blocker use, calcium channel blocker use, and ACEi/ARB/ARNi use.

Stepwise regression was performed to identify variables for multivariate regression. In multivariate analysis, clinic type, established diagnosis of hypertension, and SBP remained independently associated with the primary outcome.

\section{DISCUSSION}

This study demonstrated that cardiology fellows were better at accurately assessing BP threshold for diagnosis of hypertension and hypertension treatment goals as specified by 2017 ACC/AHA hypertension guidelines than internal medicine residents even after adjusting for baseline characteristics differences between the 2 clinics. Besides the type of clinic in which the patients were assessed, the 2 other factors that were independently associated with the primary outcome were SBP and history of hypertension.

Hypertension, known to be associated with significant cardiovascular events and increased mortality, ${ }^{13,14}$ is an important modifiable risk factor. ${ }^{15}$ Several factors can lead to uncontrolled hypertension, including nonadherence to antihypertensives, unsupportive health care systems, socioeconomic barriers to accessing health care, and physician inertia. ${ }^{16}$ Physician, or therapeutic, inertia is defined as the failure of health care providers to initiate or advance therapy when therapeutic goals are not met and has been well described with hypertension. ${ }^{17,18}$ With respect to clinicianspecific factors, the initial step in management of new-onset or existing hypertension is recognizing when the $\mathrm{BP}$ is above the recommended goal, which was the intent of this study.

The cardiology fellow clinic had a higher percentage of patients with an established diagnosis of hypertension, known ASCVD, and other cardiovascular comorbidities (congestive heart failure and atrial fibrillation), and perhaps as a result, patients had higher use of antihypertensives, aspirin, and statins. Interestingly, patients' lipid profiles, ASCVD 10-year risk profile among patients without known ASCVD, and prevalence of diabetes and CKD were similar between the 2 clinics. Despite adjusting for the differences, clinic type was independently associated with the primary outcome. Cardiology fellows were 3.6 times more likely to accurately assess uncontrolled BP compared to internal medicine residents. We hypothesize that this difference may be attributable to increased years of specific graduate training and focused cardiovascular care in the cardiology clinic.

Established diagnosis of hypertension was also independently associated with the primary outcome, suggesting that trainees were more likely to accurately assess elevated BP in a patient with diagnosed hypertension than in a patient with an initial encounter whose BP is in the hypertensive range. In such cases, hypertension may not be the primary reason for the encounter and tends to be overlooked. We believe such encounters are missed opportunities for diagnosing new hypertensive patients and initiating measures early to prevent negative cardiovascular outcomes.

We found a strong association between SBP and the primary outcome in this study. For every $1 \mathrm{mmHg}$ increase 
Mahato, $P$

Table 1. Baseline Characteristics of Patients by Clinic

\begin{tabular}{|c|c|c|c|}
\hline Variable & $\begin{array}{l}\text { Cardiology Fellow Clinic, } \\
\qquad n=127\end{array}$ & $\begin{array}{l}\text { Internal Medicine Resident Clinic, } \\
\qquad \mathrm{n}=435\end{array}$ & $P$ Value \\
\hline Age, years, mean $\pm S D$ & $57 \pm 14$ & $59 \pm 15$ & 0.19 \\
\hline Female & $61(48.0)$ & $302(69.4)$ & $<0.001$ \\
\hline Black/African American ${ }^{a}$ & $30 / 123(24.4)$ & $71 / 430(16.5)$ & 0.045 \\
\hline Body mass index, $\mathrm{kg} / \mathrm{m}^{2}$, mean $\pm \mathrm{SD}$ & $30.6 \pm 7.1$ & $29.8 \pm 6.7$ & 0.25 \\
\hline Tobacco use & & & 0.34 \\
\hline Never smoker & $72(56.7)$ & $252(57.9)$ & \\
\hline Former smoker & $45(35.4)$ & $132(30.3)$ & \\
\hline Current smoker & $10(7.9)$ & $51(11.7)$ & \\
\hline \multicolumn{4}{|l|}{ Comorbidities } \\
\hline Diagnosed hypertension & $93(73.2)$ & $256(58.9)$ & 0.003 \\
\hline Coronary artery disease & $33(26.0)$ & $46(10.6)$ & $<0.001$ \\
\hline Peripheral artery disease & $1(0.8)$ & $6(1.4)$ & 0.6 \\
\hline Cerebrovascular accident & $7(5.5)$ & $23(5.3)$ & 0.92 \\
\hline Diabetes mellitus & $36(28.3)$ & $131(30.1)$ & 0.7 \\
\hline Chronic kidney disease & $6(4.7)$ & $40(9.2)$ & 0.11 \\
\hline Congestive heart failure & $20(15.7)$ & $16(3.7)$ & $<0.001$ \\
\hline Atrial fibrillation & $13(10.2)$ & $16(3.7)$ & 0.003 \\
\hline Obstructive sleep apnea & $7(5.5)$ & $15(3.4)$ & 0.29 \\
\hline \multicolumn{4}{|l|}{ Blood pressure } \\
\hline $\mathrm{SBP}, \mathrm{mmHg}$, mean $\pm \mathrm{SD}$ & $132.5 \pm 6.7$ & $131.0 \pm 7.3$ & 0.042 \\
\hline $\mathrm{DBP}, \mathrm{mmHg}$, mean $\pm \mathrm{SD}$ & $78.9 \pm 7.7$ & $80.8 \pm 5.9$ & 0.004 \\
\hline Isolated SBP elevation ${ }^{\mathrm{b}}$ & $47(37.0)$ & $108(24.8)$ & 0.007 \\
\hline Isolated DBP elevation ${ }^{c}$ & $32(25.2)$ & $157(36.1)$ & 0.022 \\
\hline \multicolumn{4}{|l|}{ Lipid panel } \\
\hline $\mathrm{LDL}, \mathrm{mg} / \mathrm{dL}$, mean $\pm \mathrm{SD}$ & $101.0 \pm 43.3$ & $108.9 \pm 42.0$ & 0.078 \\
\hline $\mathrm{HDL}, \mathrm{mg} / \mathrm{dL}$, mean $\pm \mathrm{SD}$ & $50.2 \pm 16.2$ & $51.5 \pm 14.8$ & 0.42 \\
\hline Total cholesterol, $\mathrm{mg} / \mathrm{dL}$, mean $\pm \mathrm{SD}$ & $175.9 \pm 50.4$ & $184.1 \pm 48.1$ & 0.11 \\
\hline Antihypertensive use & $87(68.5)$ & $247(56.8)$ & 0.014 \\
\hline Thiazide & $16(12.6)$ & $70(16.1)$ & 0.34 \\
\hline Beta-blocker & $57(44.9)$ & $68(15.6)$ & $<0.001$ \\
\hline Calcium channel blocker & $32(25.2)$ & $91(20.9)$ & 0.31 \\
\hline $\mathrm{ACEi} / \mathrm{ARB} / \mathrm{ARNi}$ & $69(54.3)$ & $174(40.0)$ & 0.004 \\
\hline Aspirin & $54(42.5)$ & $139(32.0)$ & 0.027 \\
\hline Statin & $80(63.0)$ & $216(49.7)$ & 0.008 \\
\hline \multicolumn{4}{|c|}{ Atherosclerotic cardiovascular disease (ASCVD) } \\
\hline Established ASCVD & $37(29.1)$ & $64(14.7)$ & $<0.001$ \\
\hline ASCVD 10-year risk, \% ${ }^{\mathrm{d}}$ & & & 0.26 \\
\hline$<10$ & $30(23.6)$ & $156(35.9)$ & \\
\hline$\geq 10$ & $29(22.8)$ & $109(25.1)$ & \\
\hline Unable to calculate $\mathrm{e}^{\mathrm{e}}$ & $31(24.4)$ & $106(24.4)$ & 0.144 \\
\hline ASCVD 10-year risk, \%, median [IQR] & $9.8(4.7,16.1)$ & $8.6(4.1,16.4)$ & 0.57 \\
\hline
\end{tabular}

a Race data could not be confirmed for 4 patients in the cardiology fellow clinic and 5 patients in the internal medicine resident clinic.

${ }^{\mathrm{b}}$ Isolated SBP elevation, patients with SBP $\geq 130 \mathrm{mmHg}$ and DBP $<80 \mathrm{mmHg}$.

cIsolated DBP elevation, patients with SBP $<130 \mathrm{mmHg}$ and DBP $\geq 80 \mathrm{mmHg}$.

${ }^{\mathrm{d} A S C V D} 10-y e a r$ risk was only calculated for people without established ASCVD.

e Unable to calculate ASCVD because of age $<40$ years, age $>79$ years, inadequate data including lipid panel and race information, and total cholesterol $<130 \mathrm{mg} / \mathrm{dL}$ or $>320 \mathrm{mg} / \mathrm{dL}$.

Note: Data are presented as $n(\%)$ unless otherwise noted.

ACEi, angiotensin-converting enzyme inhibitor; ARB, angiotensin receptor blocker; ARNi, angiotensin receptor neprilysin inhibitor; ASCVD, atherosclerotic cardiovascular disease; DBP, diastolic blood pressure; HDL, high-density lipoprotein; IQR, interquartile range; LDL, low-density lipoprotein; SBP, systolic blood pressure. 


\begin{tabular}{|c|c|c|c|}
\hline Outcome & $\begin{array}{c}\text { Cardiology Fellow } \\
\text { Clinic, } \\
\mathbf{n = 1 2 7}\end{array}$ & $\begin{array}{l}\text { Internal Medicine } \\
\text { Resident Clinic, } \\
n=435\end{array}$ & P Value \\
\hline \multicolumn{4}{|l|}{ Primary outcome } \\
\hline $\begin{array}{l}\text { Accurate assessment of uncontrolled blood pressure in } \\
\text { accordance with } 2017 \text { ACC/AHA guidelines }\end{array}$ & $37(29.1)$ & $45(10.3)$ & $<0.001$ \\
\hline \multicolumn{4}{|l|}{ Secondary outcomes } \\
\hline Home blood pressure monitor prescription & $5(3.9)$ & $10(2.3)$ & 0.31 \\
\hline Lifestyle changes & $0(0.0)$ & $15(3.4)$ & 0.034 \\
\hline New antihypertensive medication prescription & $5(3.9)$ & $5(1.1)$ & 0.037 \\
\hline Uptitration of antihypertensives & $10(7.9)$ & $3(0.7)$ & $<0.001$ \\
\hline Antihypertensive medication reconciliation & $5(3.9)$ & $2(0.5)$ & 0.002 \\
\hline Consult to cardiology/hypertension nurse & $0(0.0)$ & $3(0.7)$ & 0.35 \\
\hline Reassessment at next visit & $13(10.2)$ & $13(3.0)$ & $<0.001$ \\
\hline
\end{tabular}

Note: Data are presented as $\mathrm{n}(\%)$.

ACC, American College of Cardiology; AHA, American Heart Association.

in SBP, the odds of accurate assessment of uncontrolled BP increased by $17 \%$. In univariate analysis, isolated elevated DBP was associated with significantly lower odds of achieving the primary outcome, but this correlation was no longer significant after adjusting for SBP in the multivariate analysis. Overall, the study suggests that physicians in this study placed a greater importance on SBP than DBP when addressing hypertension, which could be explained in part by the fact that while the recommendation for an SBP goal of $<130 \mathrm{mmHg}$ was based on a meta-analysis by the Evidence Review Committee, ${ }^{19}$ data are mixed on the association of diastolic hypertension with cardiovascular outcomes, ${ }^{20,21}$ and the DBP goal of $<80 \mathrm{mmHg}$ was based on expert opinion. ${ }^{3}$

In this study, internal medicine residents focused on lifestyle changes, whereas cardiology fellows tended to make pharmacologic interventions. This difference is not unexpected, as cardiology clinic is often a referral clinic, and patients have likely had nonpharmacologic interventions before presenting to the clinic. Because of the small number of events, we did not adjust individual interventions for baseline differences between the 2 clinics. The higher proportion of patients with established atherosclerotic diseases and known hypertension seen in the cardiology fellow clinic was possibly associated with the higher number of medicationrelated interventions compared to the internal medicine resident clinic.

The overall compliance rates among the trainee physicians in this study are far lower-29.1\% in the cardiology fellow clinic and $10.3 \%$ in the internal medicine resident clinicthan the compliance rates reported in the studies of previous guidelines. ${ }^{6-8}$ Possible causes could be lack of awareness about the current guidelines among trainees, disagreement with the 2017 ACC/AHA BP guidelines, conflicting hypertension guidelines, ${ }^{22,23}$ insufficient patient encounter time, hypertension not being the primary reason for patient encounter, or physician inertia. We theorize that by excluding the population that would have met JNC 8 criteria, our study identifies a population subset that is easily missed when seen in an ambulatory setting. This study suggests that the inadequate rate of compliance with BP goals by trainee physicians is a potential barrier to adequate control of hypertension in the population and represents an area for improvement.

Our study has several limitations. This retrospective study relied on information in the electronic medical records. Hence, if physicians recognized that BP was uncontrolled but did not indicate that in their notes, we could not accurately assess those encounters. Recorded race data for patients with Hispanic ethnicity were not reliable and hence not collected. ASCVD 10-year risk could not be calculated for some patients because of insufficient data, but the proportion of patients for whom ASCVD 10-year risk was not calculated was similar in both clinics. Because our study was retrospective, we were not able to assess the knowledge of the physicians regarding hypertension guidelines with a questionnaire beforehand, preventing us from definitively concluding that lack of awareness regarding the 2017 ACC/AHA guidelines among physicians contributed to the difference in assessment between the 2 clinics. Our study was a single-center study, so the results may not be generalizable to other centers. We are also limited in being able to comment on whether interventions such as focused lectures to trainees or programmed electronic medical record prompts for $\mathrm{BP} \geq 130 / 80 \mathrm{mmHg}$ would help improve BP assessment and eventually cardiovascular outcomes. These questions can be addressed by future prospective trials or quality improvement projects.

\section{CONCLUSION}

In this retrospective study, cardiology fellows were better at identifying hypertension diagnosis thresholds and BP treatment goals in accordance with 2017 ACC/AHA hypertension guidelines compared to internal medicine residents. SBP and history of hypertension were also independently associated with accurate assessment of 
Table 3. Primary Outcome Logistic Regression Analyses

\begin{tabular}{|c|c|c|c|c|}
\hline Variable & $\begin{array}{c}\text { Univariate } \\
\text { Analysis, } \\
\text { Odds Ratio } \\
(95 \% \mathrm{Cl})\end{array}$ & P Value & $\begin{array}{c}\text { Multivariate } \\
\text { Analysis, } \\
\text { Odds Ratio } \\
\text { (95\% Cl) }\end{array}$ & $P$ Value \\
\hline Internal medicine resident clinic & $0.28(0.17-0.45)$ & $<0.001$ & $0.27(0.16-0.47)$ & $<0.001$ \\
\hline Age & $1.02(1.0-1.04)$ & 0.004 & & \\
\hline Female & $0.73(0.45-1.19)$ & 0.216 & & \\
\hline Black/African American & $1(0.54-1.84)$ & 0.988 & & \\
\hline Body mass index & $0.99(0.95-1.02)$ & 0.683 & & \\
\hline Active tobacco use & $0.86(0.6-1.23)$ & 0.419 & & \\
\hline Diagnosed hypertension & $3.43(1.88-6.28)$ & $<0.001$ & $2.06(1.06-3.99)$ & $<0.001$ \\
\hline Coronary artery disease & $1.6(0.87-2.94)$ & 0.127 & & \\
\hline Peripheral artery disease & $0.97(0.11-8.2)$ & 0.982 & & \\
\hline Cerebrovascular accident & $1.5(0.59-3.79)$ & 0.391 & & \\
\hline Diabetes mellitus & $0.73(0.42-1.25)$ & 0.255 & & \\
\hline Chronic kidney disease & $1.25(0.56-2.8)$ & 0.575 & & \\
\hline Congestive heart failure & $1.74(0.76-3.97)$ & 0.185 & & \\
\hline Atrial fibrillation & $0.93(0.31-2.75)$ & 0.901 & & \\
\hline Obstructive sleep apnea & $1.76(0.63-4.93)$ & 0.276 & & \\
\hline SBP & $1.17(1.12-1.22)$ & $<0.001$ & $1.16(1.11-1.22)$ & 0.031 \\
\hline DBP & $0.98(0.95-1.02)$ & 0.573 & & \\
\hline Isolated SBP elevation & $1.35(0.81-2.23)$ & 0.242 & & \\
\hline Isolated DBP elevation & $0.15(0.06-0.33)$ & $<0.001$ & & \\
\hline LDL & $0.99(0.99-1.00)$ & 0.351 & & \\
\hline HDL & $1.00(0.99-1.01)$ & 0.589 & & \\
\hline Antihypertensive use & $2.54(1.47-4.38)$ & 0.001 & & \\
\hline Thiazide & $0.83(0.42-1.65)$ & 0.608 & & \\
\hline Beta-blocker & $2.33(1.41-3.86)$ & 0.001 & & \\
\hline Calcium channel blocker & $1.83(1.09-3.07)$ & 0.021 & & \\
\hline ACEi/ARB/ARNi & $2.32(1.43-3.75)$ & 0.001 & & \\
\hline Aspirin & $1.43(0.88-2.3)$ & 0.143 & & \\
\hline Statin & $1.24(0.77-1.99)$ & 0.362 & & \\
\hline Established ASCVD & $1.46(0.83-2.57)$ & 0.187 & & \\
\hline ASCVD 10-year risk & $1.02(0.99-1.04)$ & 0.069 & & \\
\hline ASCVD $\geq 10 \%$ & $1.82(0.97-3.4)$ & 0.059 & & \\
\hline
\end{tabular}

ACEi, angiotensin-converting enzyme inhibitor; ARB, angiotensin receptor blocker; ARNi, angiotensin receptor neprilysin inhibitor; ASCVD, atherosclerotic cardiovascular disease; DBP, diastolic blood pressure; HDL, high density lipoprotein; LDL, low density lipoprotein; SBP, systolic blood pressure.

uncontrolled BP. We hope this study establishes a foundation for future studies examining educational tools to improve assessment and management of hypertension by trainee physicians.

\section{ACKNOWLEDGMENTS}

The abstract for this study was published in the Journal of the American College of Cardiology on March 2020 (Volume 75, Issue 11 Supplement 1) as a part of conference proceedings. We have extended our study scope and results since that time. The authors have no financial or proprietary interest in the subject matter of this article.

\section{REFERENCES}

1. Chobanian AV, Bakris GL, Black HR, et al; National Heart, Lung, and Blood Institute Joint National Committee on Prevention, Detection, Evaluation, and Treatment of High Blood Pressure; National High Blood Pressure Education Program Coordinating Committee. The seventh report of the Joint National Committee on prevention, detection, evaluation, and treatment of high blood pressure: the JNC 7 report. JAMA. 2003;289(19):2560-72. doi: 10.1001/jama.289.19.2560

2. Armstrong C; Joint National Committee. JNC8 guidelines for the management of hypertension in adults. Am Fam Physician. 2014;90(7):503-504. 
3. Whelton PK, Carey RM, Aronow WS, et al. 2017 ACC/AHA/AAPA/ABC/ACPM/AGS/APhA/ASH/ASPC/NMA/PCNA guideline for the prevention, detection, evaluation, and management of high blood pressure in adults: executive summary: a report of the American College of Cardiology/American Heart Association Task Force on Clinical Practice Guidelines. Hypertension. 2018;71(6):1269-1324. doi: 10.1161/HYP.0000000000000066

4. Wright JT Jr, Williamson JD, Whelton PK, et al; SPRINT Research Group. A randomized trial of intensive versus standard blood-pressure control. N Engl J Med. 2015;373(22):2103-2116. doi: 10.1056/NEJMoa1511939

5. Milchak JL, Carter BL, James PA, Ardery G. Measuring adherence to practice guidelines for the management of hypertension: an evaluation of the literature. Hypertension. 2004;44(5):602-608. doi: 10.1161/01.HYP.0000144100.29945.5e

6. Alfaleh AS, Alsaidan AMA, Alsaidan AA, Albadi AMM, Wani FA, Banday $\mathrm{AH}$. Adherence of primary health care physicians to hypertension management guidelines in Aljouf region of Saudi Arabia. Int J Sci Stud. 2015;3(9):83-89.

7. Ardery G, Carter BL, Milchak JL, et al. Explicit and implicit evaluation of physician adherence to hypertension guidelines. J Clin Hypertens (Greenwich). 2007;9(2):113-119. doi: 10.1111/j.1524-6175.2007.06112.x

8. Jami P, Smith P, Moningi S, et al. Compliance with Joint National Committee 7 guidelines in hypertension management in a teaching institution. Am J Med Qual. 2007;22(4):251-258. doi: 10.1177/1062860607303293

9. Khera R, Lu Y, Lu J, et al. Impact of 2017 ACC/AHA guidelines on prevalence of hypertension and eligibility for antihypertensive treatment in United States and China: nationally representative cross sectional study. BMJ. 2018;362:k2357. doi: 10.1136/bmj.k2357

10. Goff DC Jr, Lloyd-Jones DM, Bennett G, et al; American College of Cardiology/American Heart Association Task Force on Practice Guidelines. 2013 ACC/AHA guideline on the assessment of cardiovascular risk: a report of the American College of Cardiology/American Heart Association Task Force on Practice Guidelines. Circulation. 2014;129(25 Suppl 2):S49-S73.

11. ASCVD Risk Estimator Plus. American College of Cardiology. Accessed June 23, 2021. http://tools.acc.org/ASCVD-Risk-Estimator-Plus

12. Challa HJ, Ameer MA, Uppaluri KR. DASH diet to stop hypertension. In: StatPearls [Internet]. May 19, 2021. https://pubmed.ncbi.nlm.nih.gov/29494120/
13. Rapsomaniki E, Timmis A, George J, et al. Blood pressure and incidence of twelve cardiovascular diseases: lifetime risks, healthy life-years lost, and age-specific associations in 1.25 million people. Lancet. 2014;383(9932):1899-1911. doi: 10.1016/S0140-6736(14)60685-1

14. Lawes CMM, Vander Hoorn S, Rodgers A; International Society of Hypertension. Global burden of blood-pressure-related disease, 2001. Lancet. 2008;371(9623):1513-1518. doi: 10.1016/S0140-6736(08)60655-8

15. GBD 2017 Risk Factor Collaborators. Global, regional, and national comparative risk assessment of 84 behavioural, environmental and occupational, and metabolic risks or clusters of risks for 195 countries and territories, 1990-2017: a systematic analysis for the Global Burden of Disease Study 2017. Lancet. 2018;392(10159):1923-1994. doi: 10.1016/S0140-6736(18)32225-6

16. Redon J, Mourad JJ, Schmieder RE, Volpe M, Weiss TW. Why in 2016 are patients with hypertension not $100 \%$ controlled? A call to action. J Hypertens. 2016;34(8):1480-1488. doi: $10.1097 / \mathrm{HJH} .000000000000098$

17. Lebeau JP, Cadwallader JS, Aubin-Auger I, et al. The concept and definition of therapeutic inertia in hypertension in primary care: a qualitative systematic review. BMC Fam Pract. 2014;15:130. doi: 10.1186/1471-2296-15-130

18. Moser M. Physician or clinical inertia: what is it? Is it really a problem? And what can be done about it? J Clin Hypertens (Greenwich). 2009;11(1):1-4. doi: $10.1111 / j .1751-7176.2008 .00047 . x$

19. Reboussin DM, Carey RM, Whelton PK. Evidence supporting the blood pressure treatment goal of less than $130 / 80 \mathrm{~mm} \mathrm{Hg}$. Hypertension. 2019;73(5):972-974. doi: 10.1161/HYPERTENSIONAHA.119.12804

20. Kostis WJ, Kostis JB, Moreyra AE. Systolic and diastolic blood pressure and cardiovascular outcomes. NEngl J Med. 2019;381(17):1690. doi: 10.1056/NEJMc1911059

21. McEvoy JW, Daya N, Rahman F, et al. Association of isolated diastolic hypertension as defined by the 2017 ACC/AHA blood pressure guideline with incident cardiovascular outcomes. JAMA. 2020;323(4):329-338. doi: 10.1001/jama.2019.21402

22. Williams B, Mancia G, Spiering W, et al; ESC Scientific Document Group. 2018 ESC/ESH guidelines for the management of arterial hypertension. Eur Heart J. 2018;39(33):3021-3104. doi: 10.1093/eurheartj/ehy339

23. Unger T, Borghi C, Charchar F, et al. 2020 International Society of Hypertension Global Hypertension Practice guidelines. Hypertension. 2020;75(6):1334-1357. doi: 10.1161/HYPERTENSIONAHA.120.15026

This article meets the Accreditation Council for Graduate Medical Education and the American Board of Medical Specialties Maintenance of Certification competencies for Patient Care, Medical Knowledge, and Practice-Based Learning and Improvement.

(02021 by the author(s); licensee Ochsner Journal, Ochsner Clinic Foundation, New Orleans, LA. This article is an open (c) (i) access article distributed under the terms and conditions of the Creative Commons Attribution (CC BY) license (creativecommons.org/licenses/by/4.0/legalcode) that permits unrestricted use, distribution, and reproduction in any medium, provided the original author(s) and source are credited. 